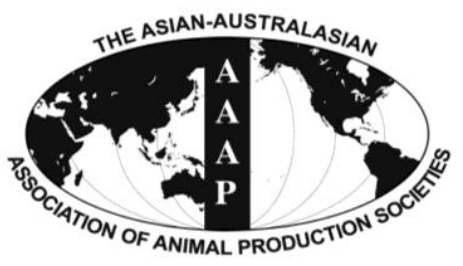

Open Access

Asian Australas. J. Anim. Sci.

Vol. 27, No. 11 : 1600-1607 November 2014

http://dx.doi.org/10.5713/ajas.2014.14356

www.ajas.info

pISSN 101 1-2367 elSSN 1976-5517

\title{
Protected Organic Acid Blends as an Alternative to Antibiotics in Finishing Pigs
}

\author{
S. D. Upadhaya, K. Y. Lee ${ }^{1}$, and I. H. Kim* \\ Department of Animal Resource and Science, Dankook University, Cheonan 330-714, Korea
}

\begin{abstract}
A total of 120 finishing pigs ([YorkshirexLandrace] $\times$ Duroc) with an average body weight (BW) of $49.72 \pm 1.72 \mathrm{~kg}$ were used in 12-wk trial to evaluate the effects of protected organic acids on growth performance, nutrient digestibility, fecal micro flora, meat quality and fecal gas emission. Pigs were randomly allotted to one of three dietary treatments (10 replication pens with 4 pigs per pen) in a randomly complete block design based on their initial BW. Each dietary treatment consisted of: Control (CON/basal diet), OA1 (basal diet $+0.1 \%$ organic acids) and OA2 (basal diet $+0.2 \%$ organic acids). Dietary treatment with protected organic acid blends linearly improved ( $\mathrm{p}<0.001)$ average daily gain during 0 to 6 week, 6 to 12 week as well as overall with the increase in their inclusion level in the diet. The dry matter, N, and energy digestibility was higher (linear effect, $p<0.001$ ) with the increase in the dose of protected organic acid blends during 12 week. During week 6, a decrease (linear effect, $\mathrm{p}=0.01$ ) in fecal ammonia contents was observed with the increase in the level of protected organic acid blends on d 3 and d 5 of fermentation. Moreover, acetic acid emission decreased linearly $(\mathrm{p}=0.02)$ on $\mathrm{d} 7$ of fermentation with the increase in the level of protected organic acid blends. During 12 weeks, linear decrease $(p<0.001)$ in fecal ammonia on d 3 and d 5 and acetic acid content on d 5 of fermentation was observed with the increase in the level of protected organic acid blends. Supplementation of protected organic acid blends linearly increased the longissimus muscle area with the increasing concentration of organic acids. Moreover, color of meat increased (linear effect, quadratic effect, $p<0.001, p<0.002$ respectively) and firmness of meat showed quadratic effect $(\mathrm{p}=0.003)$ with the inclusion of increasing level of protected organic acid in the diet. During the 6 week, increment in the level of protected organic acid blends decreased (linear effect, $\mathrm{p}=0.01$ ) Escherichia coli (E. coli) counts and increased (linear effect, $\mathrm{p}=0.004)$ Lactobacillus counts. During 12-wk of experimental trial, feces from pigs fed diet supplemented with organic acid blends showed linear reduction $(\mathrm{p}<0.001)$ of $E$. coli counts and the tendency of linear increase $(\mathrm{p}=$ 0.06) in Lactobacillus count with the increase in the level of organic acid blends. In conclusion, $0.2 \%$ protected organic acids blends positively affected growth performance, nutrient digestibility, fecal gas emission and meat quality in finishing pigs without any adverse effects on blood parameters. (Key Words: Digestibility, Finishing Pigs, Growth Performance, Micro Flora, Protected Organic Acids)
\end{abstract}

\section{INTRODUCTION}

The risk of bacterial resistance to specific antibiotics led to a ban of antibiotics as growth promoters since 2006 in the European Union. In recent decades, organic acids among other feed additives have been used as potential alternatives to antibiotics in monogastric animals' diets. Several researchers reported that dietary inclusion of organic acids have positive effects in improving growth rate

\footnotetext{
* Corresponding Author: In Ho Kim. Tel: +82-41-550-3652, Fax: +82-41-565-2949, E-mail: inhokim@ dankook.ac.kr

${ }^{1}$ Morningbio Co., LTD., Cheonan 331-963, Korea.

Submitted May 15, 2014; Revised Jun. 11, 2014; Accepted Aug. 14, 2014
}

and feed efficiency (Eckel et al., 1992; Overland et al., 2008), but others reported negative responses or no effect of organic acid inclusion in the diet (Radecki et al., 1988; Manzanilla et al., 2004). The effectiveness of unprotected organic acid may be limited due to prompt absorption and metabolism in the duodenum which eventually influences modulation of intestinal flora. A study by Bosi et al. (1999) has shown that protected organic acid led to lower Escherichia coli (E. coli) counts in the ileum and higher Lactobacillus counts in the colon indicating that protected organic acid is more effective in retarding absorption of dietary acids and allowing more effective delivery of acids to the distal ileum, caecum and colon of piglets. Besides organic acids, medium chain fatty acids (MCFA) having 6

Copyright (? 2014 by Asian-Australasian Journal of Animal Sciences This is an open-access article distributed under the terms of the Creative Commons Attribution Non-Commercial License (http://creativecommons.org/licenses/by-nc/3.0/), which permits unrestricted non-commercial use, distribution, and reproduction in any medium, provided the original work is properly cited. 
to10 carbon atoms also have antimicrobial property. Dierick et al. (2002) reported that about $80 \%$ of the MCFA may exert bacteriostatic and bactericidal properties in the upper small intestine. Thus, it was assumed that including MCFA along with organic acid blends would enhance its antimicrobial effects. Therefore, we hypothesized that the blends of different organic acids with MCFA in matrix coating could play an influential role in improving growth performance, meat quality and microbial population of finishing pigs. Furthermore, dietary acidifiers have been widely used in piglets and there is limited study on the effect of organic acids in finishing pigs. Thus, the objectives of the present study were the development of a novel composition of organic acid blends and MCFA protected by lipid base matrix coating and evaluation of its impact on the growth performance, nutrient digestibility, blood characteristics, meat quality, fecal gas emission and fecal micro flora in the finishing pigs.

\section{MATERIALS AND METHODS}

The experimental protocols describing the management and care of animals were reviewed and approved by the Animal Care and Use Committee of Dankook University.

\section{Source of organic acid}

The matrix coated organic acid, used in the current experiment was provided by a commercial company (Morningbio Co., Ltd., Cheonan, Korea). This protected organic acid consists of MCFA and composite organic acids. The active ingredients were $17 \%$ fumaric acid, $13 \%$ citric acid, $10 \%$ malic acid, 1.2\% MCFA (capric and caprylic acid) and carrier.

\section{Experimental design, animals, and diets}

A total of 120 finishing pigs ([Yorkshire $\times$ Landrace] $\times$ Duroc) with an average body weight (BW) of $49.72 \pm 1.72$ $\mathrm{kg}$ were used in this 12-wk growth trial. Pigs were allotted to 3 dietary treatments based on their initial BW. Each dietary treatment consisted of CON (basal diet), OA1 (basal diet+0.1\% organic acids) and OA2 (basal diet $+0.2 \%$ organic acids). Pigs were randomly allotted to one of three treatments (10 replication pens with 4 pigs per pen) in a randomized complete block design. Diets (Table 1) were formulated to meet or exceed the nutrient requirements recommended by NRC (1998). Organic acid blends in the form of powder were added to the diet at the expense of corn using a mixing machine. All pigs were provided with ad libitum access to feed and water through a self-feeder and nipple drinker, respectively, throughout the experiment. The target room temperature and humidity were $25^{\circ} \mathrm{C}$ and $60 \%$ respectively.
Table 1. Compositions of basal diets for finishing pigs (as-fed basis)

\begin{tabular}{|c|c|}
\hline Items & Content \\
\hline \multicolumn{2}{|l|}{ Ingredients $(\mathrm{g} / \mathrm{kg})$} \\
\hline Ground corn & 589.3 \\
\hline Soybean meal (CP 47.5\%) & 316.8 \\
\hline Tallow & 27.9 \\
\hline Molasses & 30.0 \\
\hline Limestone & 3.6 \\
\hline Dicalcium phosphate & 18.4 \\
\hline Salt & 1.5 \\
\hline L-lys $\cdot \mathrm{HCl}(78 \%)$ & 2.7 \\
\hline DL-met & 1.0 \\
\hline L-thr $(89 \%)$ & 0.7 \\
\hline Choline chloride (25\%) & 1.1 \\
\hline Vitamin premix $^{1}$ & 1.3 \\
\hline Trace mineral premix ${ }^{2}$ & 2.0 \\
\hline \multicolumn{2}{|l|}{ Calculated composition } \\
\hline $\mathrm{DE}(\mathrm{MJ} / \mathrm{kg})$ & 14.7 \\
\hline $\mathrm{CP}$ & 176.3 \\
\hline $\mathrm{Ca}$ & 7.0 \\
\hline Available P & 6.3 \\
\hline Lys & 10.2 \\
\hline Met+cys & 9.2 \\
\hline \multicolumn{2}{|l|}{ Analyzed composition } \\
\hline $\mathrm{CP}$ & 174.1 \\
\hline $\mathrm{Ca}$ & 7.8 \\
\hline Available P & 6.1 \\
\hline Lys & 10.9 \\
\hline Met+cys & 9.7 \\
\hline
\end{tabular}

$\mathrm{CP}$, crude protein; DE, digestible energy.

${ }^{1}$ Provided per kg of complete diet: vitamin A, 4,000 IU; vitamin $\mathrm{D}_{3}, 800$ IU; vitamin E, $171 \mathrm{IU}$; vitamin K, $2 \mathrm{mg}$; riboflavin, $4 \mathrm{mg}$; niacin, $20 \mathrm{mg}$; thiamine, $4 \mathrm{mg}$; d-pantothenic, $11 \mathrm{mg}$; choline, $166 \mathrm{mg}$; biotin, $0.08 \mathrm{mg}$; vitamin $\mathrm{B}_{12}, 16 \mu \mathrm{g}$.

${ }^{2}$ Provided per $\mathrm{kg}$ of complete diet: $\mathrm{Cu}$ (as $\mathrm{CuSO}_{4} \cdot 5 \mathrm{H}_{2} \mathrm{O}$ ), $15 \mathrm{mg}$; Fe (as $\mathrm{FeSO}_{4} \cdot 7 \mathrm{H}_{2} \mathrm{O}$ ), $80 \mathrm{mg}$; $\mathrm{Zn}\left(\right.$ as $\left.\mathrm{ZnSO}_{4}\right), 56 \mathrm{mg}$; $\mathrm{Mn}\left(\mathrm{MnO}_{2}\right), 74 \mathrm{mg}$; I (as $\mathrm{KI}), 0.3 \mathrm{mg}$; $\mathrm{Co}\left(\right.$ as $\left.\mathrm{CoSO}_{4} \cdot 5 \mathrm{H}_{2} \mathrm{O}\right), 0.5 \mathrm{mg}$; and $\mathrm{Se}\left(\right.$ as $\mathrm{Na}_{2} \mathrm{SeO}_{3} \cdot 5 \mathrm{H}_{2} \mathrm{O}$ ), $0.4 \mathrm{mg}$.

\section{Experimental procedures}

Body weight was measured at week 6 and week 12 of the experimental period, and feed consumption was recorded on a pen basis during the experiment to calculate the average daily gain (ADG), average daily feed intake (ADFI) and gain-to-feed (G:F) ratio. Chromium oxide was added to the diet as an indigestible marker at $0.20 \%$ of the diet for $7 \mathrm{~d}$ prior to fecal collection at the 6th week and 12th week for calculation of dry matter (DM), nitrogen (N), and energy digestibility. Fecal samples were collected randomly from at least 2 pigs in each pen. All feed and feces samples were stored immediately at $-20^{\circ} \mathrm{C}$ until analysis. All the feed and fecal samples were freeze-dried and finely ground to be able to pass through a $1 \mathrm{~mm}$ screen. The determination of DM, N, and energy was conducted in accordance with 
the methods established by the AOAC (2000). Chromium levels were determined via UV absorption spectrophotometry (UV-1201, Shimadzu, Kyoto, Japan) and the apparent total tract digestibility of DM, N, and energy were calculated using indirect methods described by Williams et al. (1962).

Two pigs were randomly selected from each pen and bled via jugular venipuncture at the beginning of the experiment ( 20 pigs per treatment at $0 \mathrm{~d}$ ). The same pigs were bled at the end of $6 \mathrm{wk}$ and $12 \mathrm{wk}$ of the experiment. Blood samples were collected into non-heparinized vacuum tubes and tubes containing $\mathrm{K}_{3}$ EDTA (Becton Dickinson Vacutainer Systems, Franklin Lakes, NJ, USA) to obtain serum and whole blood, respectively. The red blood cells (RBC), white blood cells (WBC) and lymphocyte counts of whole blood samples were determined using an automatic blood analyzer (ADVIA 120, Bayer, Tarrytown, NY, USA). The concentration of glucose in the blood serum was measured using the automatic biochemistry analyzer (HITACHI 747, Hitachi, Tokyo, Japan).

At the end of the experiment, two pigs from each pen were transported to the abattoir for slaughter. The carcasses were placed in a conventional chiller at $4^{\circ} \mathrm{C}$. After $24 \mathrm{~h}$ chill period, carcasses were fabricated into primal cuts. Meat samples, which included lean and fat, were taken via perpendicular cut loins into 2-cm-thick chop beginning from the 10th and 11th ribs region. Backfat thickness was determined by measuring midline fat thickness. The $\mathrm{pH}$ of longissimus muscle (LM) was measured in $24 \mathrm{~h}$ postmortem with an insertion glass electrode (Radiometer, Lyon, France) connected to a pH-meter (NWK binar pH, K-21, Landsberg, Germany). The electrode was calibrated at $20^{\circ} \mathrm{C}$ in buffers at $\mathrm{pH}$ value of 4.00 and 7.00. Surface LM color (Minolta $\mathrm{L}^{*}, \mathrm{a}^{*}$, and $\mathrm{b}^{*}$ ) was measured in triplicate on a freshly-cut surface with a Minolta Chromameter (Minolta CR 301, Tokyo, Japan). The water holding capacity (WHC) was measured according to the methods of Kauffman et al. (1986). In brief, $0.2 \mathrm{~g}$ sample was pressed at 3,000 psi for 3 min on 125 -mm-diameter filter paper. The areas of the pressed sample and expressed moisture were delineated and then determined with a digitizing area-line sensor (MT-10S; M. T. Precision Co. Ltd., 123 Tokyo, Japan). A ratio of water: meat areas was calculated, giving a measure of WHC (the smaller ratio indicates the higher WHC). The proportion of LM acceptable for Pork Composition and Quality Assessment Procedures (Berg, 2000) was determined via the selection of LM with acceptable color, firmness, and marbling (all measures 3 or greater based on a scale of 1 to 5, Berg, 2000). Drip loss was measured using approximately $2 \mathrm{~g}$ of meat sample according to the plastic bag method, which was described by Honikel (1998).

For Lactobacillus and E. coli population analysis, fresh feces taken via massaging the rectum from 2 pigs per pen at the last two days of period were respectively pooled and placed on ice for transportation to the laboratory. The composite fecal sample (one gram) from each pig was diluted with $9 \mathrm{~mL}$ of $1 \%$ peptone broth (Becton, Dickinson and Co., Franklin Lakes, NJ, USA) and then homogenized. Viable counts of bacteria in the fecal samples were conducted by plating serial 10 -fold dilutions (in 1\% peptone solution) onto Mac Conkey agar plates (Difco Laboratories, Detroit, MI, USA) and lactobacilli medium III agar plates (Medium 638, DSMZ, Braunschweig, Germany) to isolate the E. coli and Lactobacillus, respectively. The lactobacilli medium III agar plates were incubated for $48 \mathrm{~h}$ at $39^{\circ} \mathrm{C}$ under anaerobic conditions. The Mac Conkey agar plates were incubated for $24 \mathrm{~h}$ at $37^{\circ} \mathrm{C}$. The E. coli and Lactobacillus colonies were counted immediately after removal from the incubator.

For the analysis of the fecal $\mathrm{NH}_{3}$ and acetic acid, fresh feces were collected from 2 pigs each pen the last $2 \mathrm{~d}$ of the experiment. The total sampled feces was then thawed and homogenized, after which the stock feces were stored in 2.6-L plastic boxes in duplicate with a small hole in the middle of one side that was sealed with adhesive plaster. The samples were allowed to ferment for 1 day at room temperature $\left(25^{\circ} \mathrm{C}\right)$, after which $100 \mathrm{~mL}$ of the headspace air was sampled from approximately $2.0 \mathrm{~cm}$ above the fecal sample. Concentration of $\mathrm{NH}_{3}$ and acetic acid were measured within the scope of 5.0 to $100.0 \mathrm{ppm}$ (No. 3La, detector tube; Gastec Corp. Kanagawa, Japan). After collection, box was re-sealed with adhesive plaster to measure the fecal noxious content at d 3, d 5, and d 7. The gas emission of the sample within pig was averaged by measurements of two duplicate boxes. Prior to measurement, the fecal samples were manually shaken for approximately $30 \mathrm{~s}$ to disrupt any crust formation on the surface of the fecal sample and to homogenize the samples.

\section{Statistical analyses}

All data were subjected to statistical analysis in a randomized complete block design using the general linear model procedures (SAS Inst. Inc., Cary, NC, USA), with the pen serving as the experimental unit. The initial BW was used as a covariate for the ADFI and ADG, and the initial values were used as a covariate for the blood profile. Before conducting statistical analysis of the microbial counts, the value was transformed logarithmically. Linear and quadratic polynomial contrasts were performed to determine the effects of inclusion level of $0.1 \%$ and $0.2 \%$ of protected organic acid blends in the diet.

\section{RESULTS}

\section{Growth performance}

In the current study, linear effect of dietary treatment on 
Table 2. Effects of dietary organic acid blends on growth performance in finishing pigs

\begin{tabular}{|c|c|c|c|c|c|c|}
\hline \multirow{2}{*}{ Items } & \multirow{2}{*}{$\mathrm{CON}^{1}$} & \multirow{2}{*}{$\mathrm{OA} 1^{1}$} & \multirow{2}{*}{$\mathrm{OA} 2^{1}$} & \multirow{2}{*}{ SE } & \multicolumn{2}{|c|}{ p-value } \\
\hline & & & & & Linear & Quadratic \\
\hline \multicolumn{7}{|l|}{0 to 6 weeks } \\
\hline ADG (g) & 779 & 806 & 820 & 7.0 & $<0.001$ & 0.50 \\
\hline ADFI (g) & 2,193 & 2,243 & 2,260 & 31.0 & 0.10 & 0.70 \\
\hline $\mathrm{G} / \mathrm{F}$ & 0.355 & 0.359 & 0.363 & 0.01 & 0.30 & 1.00 \\
\hline \multicolumn{7}{|c|}{6 to 12 weeks } \\
\hline ADG (g) & 824 & 858 & 879 & 13.0 & 0.01 & 0.70 \\
\hline ADFI (g) & 2,709 & 2,718 & 2,748 & 30.0 & 0.40 & 0.80 \\
\hline $\mathrm{G} / \mathrm{F}$ & 0.304 & 0.316 & 0.320 & 0.01 & 0.08 & 0.60 \\
\hline \multicolumn{7}{|l|}{ Overall } \\
\hline ADG (g) & 801 & 832 & 849 & 7.0 & $<0.001$ & 0.50 \\
\hline ADFI (g) & 2,451 & 2,480 & 2,504 & 27.0 & 0.20 & 0.90 \\
\hline $\mathrm{G} / \mathrm{F}$ & 0.327 & 0.336 & 0.339 & $<0.01$ & 0.10 & 0.70 \\
\hline
\end{tabular}

$\mathrm{OA}$, organic acids; SE, standard error; $\mathrm{ADG}$ average daily gain; $\mathrm{ADFI}$, average daily feed intake; G/F, gain-to-feed ratio.

${ }^{1} \mathrm{CON}=$ basal diet; $\mathrm{OA} 1=\mathrm{CON}+0.1 \% \mathrm{OA} ; \mathrm{OA} 2=\mathrm{CON}+0.2 \% \mathrm{OA}$.

Values represent the means of ten pens with four pigs per pen.

ADG was observed. However, no linear or quadratic effect of dietary treatment with protected organic acid blends on ADFI and G:F was observed. The ADG increased linearly $(\mathrm{p}<0.001)$ during 0 to 6 week as well as during 6 to12 week of experimental period as the inclusion rate of protected organic acid blends increased. Overall, the increase in the inclusion level of protected organic acid blends linearly increased the ADG (Table 2).

\section{Nutrient digestibility and blood characteristics}

The DM, N, and energy digestibility was higher (linear effect, $\mathrm{p}<0.001$ ) with the increase in the inclusion level of protected organic acid blends in the diet during 12 week. However, supplementation of protected organic acid blends had no effect on nutrient digestibility during 6th week of experimental trial (Table 3). Dietary inclusion of protected organic acids blends had no effect on the blood serum parameters (WBC, RBC, lymphocyte count, glucose concentration) in the current study (Table 4).

\section{Fecal noxious gas content}

During week 6 , a decrease (linear effect, $p=0.01$ ) in fecal ammonia contents was observed with the increase in the level of protected organic acid supplementation in the current study (Table 5) on d 3 and d 5 of fermentation. Moreover, acetic acid emission decreased linearly ( $\mathrm{p}=$ 0.02 ) on $\mathrm{d} 7$ of fermentation with the increase in the level of protected organic acid blends. During 12 weeks, linear decrease $(\mathrm{p}<0.001)$ in fecal ammonia on d 3 and $d 5$ and acetic acid content on $\mathrm{d} 5$ of fermentation was observed with the increase in the level of protected organic acid blends.

\section{Meat quality and fecal microflora}

Supplementation of protected organic acid blends $(0.1 \%$ and $0.2 \%$ ) increased the LM area and there was linear effect with the increasing concentration of organic acids. Moreover, color of meat increased (linear effect, quadratic effect, $\mathrm{p}<0.001, \mathrm{p}<0.002$ respectively) and firmness of meat showed quadratic effect $(\mathrm{p}=0.003)$ with the inclusion of

Table 3. Effects of dietary organic acid blends on nutrient digestibility in finishing pigs

\begin{tabular}{|c|c|c|c|c|c|c|}
\hline \multirow{2}{*}{ Items $(\%)$} & \multirow{2}{*}{$\mathrm{CON}^{1}$} & \multirow{2}{*}{$\mathrm{OA} 1^{1}$} & \multirow{2}{*}{$\mathrm{OA} 2^{1}$} & \multirow{2}{*}{ SE } & \multicolumn{2}{|c|}{ p-value } \\
\hline & & & & & Linear & Quadratic \\
\hline \multicolumn{7}{|l|}{6 weeks } \\
\hline Dry matter & 74.42 & 76.76 & 77.53 & 2.07 & 0.30 & 0.80 \\
\hline Nitrogen & 72.90 & 75.92 & 77.82 & 2.09 & 0.10 & 0.80 \\
\hline Energy & 74.40 & 74.93 & 76.16 & 2.36 & 0.60 & 0.90 \\
\hline \multicolumn{7}{|l|}{12 weeks } \\
\hline Dry matter & 72.63 & 75.31 & 77.46 & 0.6 & $<0.001$ & 0.70 \\
\hline Nitrogen & 72.68 & 76.05 & 79.05 & 0.7 & $<0.001$ & 0.80 \\
\hline Energy & 74.3 & 78.97 & 79.43 & 0.7 & $<0.001$ & 0.03 \\
\hline
\end{tabular}

OA, organic acids; SE, standard error.

${ }^{1} \mathrm{CON}=$ basal diet; $\mathrm{OA} 1=\mathrm{CON}+0.1 \% \mathrm{OA} ; \mathrm{OA} 2=\mathrm{CON}+0.2 \% \mathrm{OA}$.

Values represent the means of ten pens with four pigs per pen. 
Table 4. Effect of dietary organic acid blends on blood profiles in finishing pigs

\begin{tabular}{|c|c|c|c|c|c|c|}
\hline \multirow{2}{*}{ Item } & \multirow{2}{*}{$\mathrm{CON}^{1}$} & \multirow{2}{*}{$\mathrm{OA} 1^{1}$} & \multirow{2}{*}{$\mathrm{OA} 2^{1}$} & \multirow{2}{*}{ SE } & \multicolumn{2}{|c|}{ p-value } \\
\hline & & & & & Linear & Quadratic \\
\hline \multicolumn{7}{|l|}{6 weeks } \\
\hline $\mathrm{RBC}\left(10^{6} / \mu \mathrm{L}\right)$ & 19.11 & 19.91 & 20.55 & 1.0 & 0.30 & 1.00 \\
\hline $\operatorname{WBC}\left(10^{3} / \mu \mathrm{L}\right)$ & 6.69 & 6.47 & 6.68 & 0.5 & 1.00 & 0.70 \\
\hline Lymphocyte (\%) & 44.95 & 43.32 & 44.07 & 2.2 & 0.80 & 0.70 \\
\hline Glucose (mg/dL) & 67.86 & 74.00 & 75.43 & 4.5 & 0.30 & 0.70 \\
\hline \multicolumn{7}{|l|}{12 weeks } \\
\hline $\operatorname{RBC}\left(10^{6} / \mu \mathrm{L}\right)$ & 20.7 & 21.4 & 22.75 & 0.8 & 0.10 & 0.80 \\
\hline $\operatorname{WBC}\left(10^{3} / \mu \mathrm{L}\right)$ & 7.36 & 7.30 & 7.39 & 0.1 & 0.90 & 0.60 \\
\hline Lymphocyte (\%) & 61.03 & 63.74 & 62.83 & 3.3 & 0.70 & 0.70 \\
\hline Glucose (mg/dL) & 63 & 64.57 & 65.14 & 3.5 & 0.30 & 0.70 \\
\hline
\end{tabular}

OA, organic acids; SE, standard error; RBC, red blood cells; WBC, white blood cells.

${ }^{1} \mathrm{CON}=$ basal diet; $\mathrm{OA} 1=\mathrm{CON}+0.1 \% \mathrm{OA} ; \mathrm{OA} 2=\mathrm{CON}+0.2 \% \mathrm{OA}$.

Values represent the means of ten pens with two pigs per pen.

increasing level of protected organic acid in the diet (Table $6)$.

During 6 week, increase in inclusion level of protected organic acid blends decreased (linear effect, $\mathrm{p}=0.01) \mathrm{E}$. coli counts and increased (linear effect, $\mathrm{p}=0.004$ ) Lactobacillus counts (Table 7). During 12-wk of experimental trial, feces from pig fed diet supplemented

Table 5. Effect of dietary organic acid blends on fecal noxious gas emission in finishing pigs

\begin{tabular}{|c|c|c|c|c|c|c|}
\hline \multirow{2}{*}{ Items $(\%)$} & \multirow{2}{*}{$\mathrm{CON}^{1}$} & \multirow{2}{*}{$\mathrm{OA} 1^{1}$} & \multirow{2}{*}{$\mathrm{OA} 2^{1}$} & \multirow{2}{*}{ SE } & \multicolumn{2}{|c|}{ p-value } \\
\hline & & & & & Linear & Quadratic \\
\hline \multicolumn{7}{|l|}{6 weeks } \\
\hline \multicolumn{7}{|c|}{ Ammonia } \\
\hline $1 \mathrm{~d}$ & 11.6 & 11.9 & 9.1 & 0.9 & 0.10 & 0.20 \\
\hline $3 \mathrm{~d}$ & 15.4 & 14.3 & 13.0 & 0.6 & 0.01 & 0.90 \\
\hline $5 \mathrm{~d}$ & 18.0 & 16.7 & 15.0 & 0.8 & 0.01 & 0.80 \\
\hline $7 \mathrm{~d}$ & 17.0 & 7.1 & 15.6 & 0.7 & 0.20 & 0.30 \\
\hline \multicolumn{7}{|c|}{ Acetic acid } \\
\hline $1 \mathrm{~d}$ & 16.5 & 16.4 & 15.5 & 0.3 & 0.10 & 0.30 \\
\hline $3 \mathrm{~d}$ & 17.6 & 18.0 & 17.4 & 0.5 & 0.70 & 0.40 \\
\hline $5 \mathrm{~d}$ & 31.2 & 32.4 & 31.2 & 0.4 & 1.00 & 0.03 \\
\hline $7 \mathrm{~d}$ & 22.8 & 22.9 & 21.7 & 0.3 & 0.02 & 0.10 \\
\hline \multicolumn{7}{|c|}{12 weeks } \\
\hline \multicolumn{7}{|c|}{ Ammonia } \\
\hline $1 \mathrm{~d}$ & 13.8 & 13.4 & 13.1 & 0.5 & 0.30 & 0.90 \\
\hline $3 d$ & 16.5 & 16.0 & 15.1 & 0.3 & 0.01 & 0.60 \\
\hline $5 \mathrm{~d}$ & 18.8 & 17.5 & 17.1 & 0.3 & $<0.001$ & 0.20 \\
\hline $7 \mathrm{~d}$ & 17.1 & 17.4 & 16.7 & 0.3 & 0.30 & 0.20 \\
\hline \multicolumn{7}{|c|}{ Acetic acid } \\
\hline $1 \mathrm{~d}$ & 16.0 & 16.4 & 15.8 & 0.5 & 0.80 & 0.40 \\
\hline $3 \mathrm{~d}$ & 18.3 & 18.7 & 17.8 & 0.5 & 0.50 & 0.30 \\
\hline $5 \mathrm{~d}$ & 33.2 & 31.5 & 30.6 & 0.5 & 0.003 & 0.50 \\
\hline $7 \mathrm{~d}$ & 23.3 & 23.2 & 21.9 & 0.5 & 0.01 & 0.30 \\
\hline
\end{tabular}

OA, organic acids; SE, standard error.

${ }^{1} \mathrm{CON}=$ basal diet; $\mathrm{OA} 1=\mathrm{CON}+0.1 \%$ organic acids; $\mathrm{OA} 2, \mathrm{CON}+0.2 \%$ organic acids

Values represent the means of ten pens with two pigs per pen. with organic acid blends showed linear reduction $(\mathrm{p}<0.001)$ of $E$. coli counts and showed the tendency of linear increase ( $\mathrm{p}=0.06)$ in Lactobacillus count with the increase in the level of organic acid blends.

\section{DISCUSSION}

Unprotected organic acid can lead to different problems such as lack of edibility (Partanen, 2001), demineralization of bones (Partanen and Mroz, 1999) damage of stomach and intestinal mucus membrane (Argenzio and Eisemann, 1996). It may also induce bacterial resistance to acids (Bearson et al., 1997). However, by protecting the organic acids by encapsulation or matrix coating they are supplied to the intestine in a non-dissociated form. It has been reported that a combination of organic acids would enhance the effectiveness of acidification, because of their dissociation ability over a wide range of $\mathrm{pH}$ values, thereby maintaining optimum $\mathrm{pH}$ through the intestinal tract (Ravindran and Kornegay, 1993). However, the effectiveness of feeding acids to pigs varies with the types and combinations of acid, the health status of the animal and feed characteristics particularly the diet's buffering capacity (Blank et al., 1999; Mroz et al., 2006). Protected organic acid used in the current study is a blend of organic acids and MCFA with matrix coating. Protection of this acid is lipid base. The supplementation of diet with organic acids has been reported to improve growth performance by reducing gastrointestinal $\mathrm{pH}$ and subsequent modification of the intestinal microflora (Kirchgessner and Roth, 1982). The present finding shows that when finishing pigs are supplemented with feed containing $0.2 \%$ protected organic acid blends such as fumaric acid, citric acid, malic acid including MCFA, their ADG improved at 6 week as well as 12 week of experimental trial. The improvement in ADG could be due to the antimicrobial activity of organic acid which helps in the reduction of pathogenic microbial 
Table 6. Effect of dietary organic acid blends on meat quality on finishing pigs

\begin{tabular}{|c|c|c|c|c|c|c|}
\hline \multirow{2}{*}{ Items } & \multirow{2}{*}{$\mathrm{CON}^{1}$} & \multirow{2}{*}{$\mathrm{OA} 1^{1}$} & \multirow{2}{*}{$\mathrm{OA} 2^{1}$} & \multirow{2}{*}{ SE } & \multicolumn{2}{|c|}{ p-value } \\
\hline & & & & & Linear & Quadratic \\
\hline $\mathrm{pH}$ & 5.72 & 5.81 & 5.72 & 0.0 & 0.90 & 0.04 \\
\hline Longissimus muscle area $\left(\mathrm{cm}^{2}\right)$ & 47.00 & 49.16 & 50.79 & 0.4 & 0.001 & 0.70 \\
\hline Water holding capacity $(\%)$ & 57.34 & 58.1 & 57.87 & 1.3 & 0.80 & 0.80 \\
\hline \multicolumn{7}{|l|}{ Meat color } \\
\hline L (Lightness) & 58.90 & 59.78 & 58.58 & 1.0 & 0.90 & 0.40 \\
\hline a (Redness) & 17.97 & 17.76 & 18.08 & 0.5 & 0.90 & 0.60 \\
\hline b (yellowness) & 10.15 & 9.33 & 9.62 & 0.5 & 0.50 & 0.40 \\
\hline Cooking loss $(\%)$ & 33.48 & 28.66 & 29.74 & 1.8 & 0.20 & 0.20 \\
\hline \multicolumn{7}{|l|}{ Sensory evaluation } \\
\hline Color & 1.16 & 2.18 & 2.08 & 0.1 & $<0.001$ & $<0.002$ \\
\hline Marbling & 1.42 & 1.47 & 1.33 & 0.1 & 0.60 & 0.50 \\
\hline Firmness & 1.59 & 1.99 & 1.70 & 0.1 & 0.30 & 0.003 \\
\hline \multicolumn{7}{|l|}{ Drip loss (\%) } \\
\hline D1 & 5.23 & 5.87 & 5.71 & 1.0 & 0.70 & 0.80 \\
\hline D3 & 9.50 & 8.56 & 9.73 & 1.6 & 0.90 & 0.60 \\
\hline D5 & 12.27 & 11.55 & 11.38 & 1.3 & 0.60 & 0.90 \\
\hline D7 & 14.56 & 13.06 & 13.88 & 1.4 & 0.70 & 0.50 \\
\hline
\end{tabular}

OA, organic acids; SE, standard error.

${ }^{1} \mathrm{CON}=$ basal diet; $\mathrm{OA} 1=\mathrm{CON}+0.1 \% \mathrm{OA} ; \mathrm{OA} 2=\mathrm{CON}+0.2 \% \mathrm{OA}$

Values represent the means of ten pens with two pigs per pen.

population growth thereby reducing the metabolic need of microbes and increasing the availability of dietary energy and nutrients to host animals. Consistent to our findings, some researchers have shown positive effects with single or blends of dietary acidifiers. For instance, supplementation of single acidifier such as formic acid or sorbic acid improved growth rate and feed efficiency as reported by Partenen and Mroz (1999); Overland et al. (2008). Likewise, Walsh et al. (2007) indicated that the addition of $0.4 \%$ organic acid blends such as fumaric, lactic, propionic, citric and benzoic acid improved growth performance and Li et al. (2008) also reported that $0.5 \%$ blends of organic acids such as butanic, fumaric and benzioic acid in the diet of weanling piglet improved growth performance. In contrast, other reports indicate no or negative responses with single acidifier such as fumaric, citric or formic acid (Radecki et al., 1988; Manzanilla et al., 2004) or blend of acidifiers such as formic acid, lactic acid and volatile fatty acids (Lee et al., 2007). The current study showed that protected organic acids blends improved nutrient digestibility during 12 week of the experimental trial. Likewise, other previous reports with different types of organic acid indicated that the inclusion of organic acid such as $2 \%$ benzoic acid (Kluge et al., 2010) in the diet of lactating sows improved the digestibility of nutrients, $0.5 \%$ phenyllactic acid (Wang et al., 2009a) improved nutrient digestibility in weanling pig and trends of egg production in laying hens (Wang et al., 2009b) and Franco et al. (2005) also reported that combination of lactic acid with formic or fumaric acids numerically increased DM digestibility in weanling pigs.
The increase in nutrient digestibility might have resulted from the increased microbial activity in the gastro intestinal tract (Yin et al., 2001). Luckstadt and Mellor (2011) indicated that protein and fat digestion is enhanced with organic acid supplementation because it stimulates exocrine pancreatic secretion of enzymes and bicarbonate. However, Kil et al. (2006) indicated that there was no positive response on nutrient digestibility with the inclusion of lactic, formic or fumaric acids in weanling pigs.

The emission of odorous gas such as ammonia as well as acetic acid from pig production facilities contributes to pollution in the environment (Zahn et al., 1997). To ensure sustainable pig production, the emission of such odorous gases should be reduced by proper management and dietary modification. In the current study, dietary supplementation of $0.2 \%$ protected organic acid blends showed favorable results in terms of reduction of odorous ammonia and acetic

Table 7. Effect of dietary organic acid blends on fecal microflora in finishing pigs

\begin{tabular}{lllllll}
\hline $\begin{array}{l}\text { Item } \\
(\log 10 \mathrm{cfu} / \mathrm{g})\end{array}$ & $\mathrm{CON}^{1}$ & $\mathrm{OA}^{1}$ & \multirow{2}{*}{$\mathrm{OA}^{1}$} & $\mathrm{SE}$ & \multicolumn{2}{c}{$\mathrm{p}$-value } \\
\cline { 6 - 7 } & & & & & Linear & Quadratic \\
\hline weeks & & & & & & \\
$\quad$ E. coli & 6.02 & 5.24 & 5.32 & 0.1 & 0.01 & 0.10 \\
$\quad$ Lactobacillus & 6.62 & 7.24 & 7.49 & 0.1 & $<0.01$ & 0.30 \\
12 weeks & & & & & & \\
$\quad$ E. coli & 5.95 & 5.33 & 5.21 & 0.1 & $<0.002$ & 0.04 \\
Lactobacillus & 6.79 & 6.84 & 7.05 & 0.1 & 0.06 & 0.50 \\
\hline
\end{tabular}

OA, organic acids; SE, standard error; E. coli, Escherichia coli.

${ }^{1} \mathrm{CON}=$ basal diet; $\mathrm{OA} 1=\mathrm{CON}+0.1 \% \mathrm{OA} ; \mathrm{OA} 2=\mathrm{CON}+0.2 \% \mathrm{OA}$.

Values represent the means of ten pens with two pigs per pen. 
gas emission. Eriksen et al. (2010) also reported that $2 \%$ benzoic acid supplementation in the diet of pigs reduced ammonia emissions in pig slurry by $60 \%$ to $70 \%$ for up to 2 month of storage. The reduction of these odorous gases could be possibly due to the reduction of pathogenic bacterial population in the gastrointestinal tract or due to enhancement of beneficial microbial activity leading to change in end products of microbial fermentation and shifting the ecosystem towards a more anabolic status. The toxic bacterial metabolites and ammonia were reduced by acidifiers with the reduction in pathogen concentration (Dibner and Buttin, 2002).

Dietary acidifiers have been broadly used worldwide in diets of animals as an alternative to antibiotic growth promoters, because of their potential to reduce the $\mathrm{pH}$ in the gastro intestinal tract which improves nutrient digestion and inhibits the invasion and proliferation of pathogenic bacteria in the gastrointestinal tract (Kil et al., 2011). The present study shows the significant increase in Lactobacillus population in week 6 of experimental period and tendency of increasing Lactobacillus population in week 12 with protected organic acid inclusion in the diet. However, E. coli population was significantly reduced in the feces obtained from pigs fed diet supplemented with protected organic acid compared with control in both experimental period ( 6 and 12 week) which is in agreement to $\mathrm{Li}$ et al. (2008) and Ahmed et al. (2014) who reported that blends of organic acid supplementation led to reduced E. coli and increased Lactobacilli concentration in weaned piglets. Furthermore, lactobacillus produces acid through fermentation thereby reducing intestinal $\mathrm{pH}$ of gut contents and benefit intestinal function. In addition they can inhibit the enteric pathogens (Vandenberg, 1993). Thus, the survival rate of $E$. coli in the present study could have been influenced by low $\mathrm{pH}$ because $E$. coli is less tolerant of acid $\mathrm{pH}$.

The present study showed that the inclusion of organic acid increased the LM area indicating the desirability of carcass. Meat color is an important index to estimate the quality of meat (Li et al., 2007). In the current study meat color was unaffected but sensory evaluation on meat color indicated improvement in color. The reason for difference in meat color compared with that of sensory evaluation is unclear. Other analyzed parameters such as $\mathrm{pH}$, drip loss, cooking loss and WHC were not affected with the inclusion of organic acid blends in the diet of weanling pigs.

\section{CONCLUSION}

In conclusion, acidification of the diet with protected organic acid blends positively affected the ADG and reduced pathogenic bacterial load. It also improved nutrient digestibility, reduced fecal emission of ammonia and acetic acid and increased beneficial bacterial counts. The better results were seen with $0.2 \%$ of inclusion level of organic acid blends.

\section{ACKNOWLEDGMENTS}

The authors would like to acknowledge the financial assistance (No. PJ 312036-3) provided by the Korea Institute of Planning and Evaluation for Technology of Food, Agriculture, Forestry and Fisheries.

\section{REFERENCES}

Ahmed, S. T., J. A. Hwang, J. Hoon, H. S. Mun, and C. J. Yang. 2014. Comparison of single and blend of acidifiers as an alternative to antibiotics on growth performance, fecal microflora and humoral immunity in weaned piglets. Asian Australas. J. Anim. Sci. 27:93-100.

AOAC. 2000. Official Methods of Analysis. 17th ed. Association of Official Analytical Chemists, Gaithersburg, MD, USA.

Argenzio, R. A. and J. Eisemann. 1996. Mechanisms of acid injury in porcine gastroesophageal mucosa. Am. J. Vet. Res. 57:564573.

Bearson, S., B. Bearson, and J. W. Foster. 1997. Acid stress responses in enterobacteria. FEMS Microb. Lett. 147:173-180.

Berg, E. P. 2000. Pork composition and quality assessment procedures. In: National Pork Producers Council (NPPC). Des Monies, IA, USA. pp. 1-38.

Blank, R., R. Mosenthin, W. C. Sauer, and S. Huang. 1999. Effect of fumaric acid and dietary buffering capacity on ileal and fecal amino acid digestibilities in early-weaned pigs. J. Anim. Sci. 77:2974-2984.

Bosi, P., H. J. Jung, I. K. Han, S. Perini, J. A. Cacciavillani, L. Casini, D. Creston, C. Gremokolini, and S. Mattuzzi. 1999. Effects of dietary buffering characteristics and protected or unprotected acids on piglet growth, digestibility and characteristics of gut content. Asian Australas J. Anim. Sci. 12:1104-1110

Dibner, J. J. and P. Buttin. 2002. Use of organic acid as a model, to study the impact of gut microflora on nutrition and metabolism. J. Appl. Poult. Res. 11:453-463.

Dierick, N. A., J. A. Decuypere, K. Molly, E. Van Beek, and E. Vanderbeke. 2002. The combined use of triacylglycerols (TAGs) containing medium chain fatty acids (MCFAs) and exogenous lipolytic enzymes as an alternative to nutritional antibiotics in piglet nutrition. II. In vivo release of MCFAs in gastric cannulated and slaughtered piglets by endogenous and exogenous lipases; effects on the luminal gut flora and growth performance. Livest. Prod. Sci. 76:1-16.

Eckel, B., M. Kirchgessner, and F. X. Roth. 1992. Influence of formic acid on daily weight gain, feed intake, feed conversion rate and digestibility. J. Anim. Physiol. Anim. Nutr. 67:93-100.

Eriksen, J., A. P. Adamsen, J. V. Norgaard, H. D. Poulsen, B. B. Jensen, and S. O. Petersen. 2010. Emissions of sulfur containing odorants, ammonia and methane from pig slurry: Effect of dietary methionine and benzoic acid. J. Environ. Qual. 39:1097-1107.

Franco, L. D., M. Fondevila, M. B. Lobera, and C. Castrillo. 2005. 
Effect of combinations of organic acids in weaned pig diets on microbial species of digestive tract contents and their response on digestibility. J. Anim. Physiol. Anim. Nutr. 89: 88-93.

Honikel, K. O. 1998. Reference methods for the assessment of physical characteristics of meat. Meat Sci. 49:447-457.

Kauffman, R. G., G. Eikelenboom, P. G. van der Wal, G. S. M. Merkus, and M. Zaar. 1986. The use of filter paper to estimate drip loss of porcine musculature. Meat.Sci. 18:191-200.

Kil, D. Y., L. G. Piao, H. F. Long, J. S. Lim, M. S. Yun, C. S. Kong, W. S. Ju, H. B. Lee, and Y. Y. Kim. 2006. Effects of organic or inorganic acid supplementation on growth performance, nutrient digestibility and white blood cell counts in weanling pigs. Asian Australas. J. Anim. Sci. 19:252-261.

Kil, D. Y., W. B. Kwon, and B. G. Kim. 2011. Dietary acidifiers in weanling pig diets: A review. Rev. Colomb. Cienc. Pecu. 24:231-247.

Kluge, H., J. Broz, and K. Eder. 2006. Effect of dietary benzoic acid on urinary $\mathrm{pH}$ and nutrient digestibility in lactating sows. Livest. Sci. 134:119-121.

Kirchgessner, M. and F. X. Roth. 1982. Fumaric acid as a feed additive in pig nutrition. Pig News Inf. 3:259-263.

Lee, D. N., S. R. Liu, Y. T. Chen, R. C. Wang, Y. S. Lin, and C. F. Weng. 2007. Effects of diets supplemented with organic acids and nucleotides on growth, immune responses and digestive tract development in weaned pigs. J. Anim. Physiol. Anim. Nutr. 91:508-518.

Li, Z., G. Yi, J. Yin, P. Sun, D. Li, and C. Knight. 2008. Effects of organic acids on growth performance, gastrointestinal $\mathrm{pH}$, intestinal microbial populations and immune responses of weaned pigs. Asian Australas. J. Anim. Sci. 21:252-261.

Li, L. L., Z. P. Hou, Y. L. Yin, Y. H. Liu, D. X. Hou, B. Zhang, G. Y. Wu, S. W. Kim, M. Z. Fan, C. B. Yang, X. F. Kong, Z. R. Tang, H. Z. Peng, D. Deng, Z. Y. Deng, M. Y. Xie, H. Xiong, P. Kang, and S. X. Wang. 2007. Intramuscular administration of zinc metallothionein to preslaughter stressed pigs improves anti-oxidative status and pork quality. Asian Australas. J. Anim. Sci. 20:761-767.

Luckstadt, C. and S. Mellor. 2011. The use of organic acids in animal nutrition, with special focus on dietary potassium diformate under European and Austral-Asian conditions. Recent Advances in Animal Nutrition. Australia. 18:123-130.

Manzanilla, E. G., J. F. Perez, M. Martin, C. Kamel, F. Baucells, and J. Gasa. 2004. Effect of plant extracts and formic acid on the intestinal equilibrium of early-weaned pigs. J. Anim. Sci. 82:3210-3218.

Mroz, Z., S. J. Koopmans, A. Bannink, A. K. Partanen, W. Krasucki, M. Overland, and S. Radcliffe. 2006. Carboxylic acids as bioregulators and gut growth promoters in nonruminants. In: Biology of Nutrition in Growing Animals (Eds. R. Mosenthin, J. Zentek, and T. Zebrowska). Vol. 4. Elsevier Limited. pp. 81-133.
NRC. 1998. Nutrient Requirement of Swine. 10th edn. National Academy Press, Washington, DC, USA.

Overland, M., N. P. Kjos, M. Borg, E. Skjerve, and H. Sorum. 2008. Organic acids in diets for entire male pigs: Effect on skatole level, microbiota in digesta, and growth performance. Livest. Sci. 115:169-178.

Partenen, K. 2001. Organic acids - Their efficacy and modes of action in pigs. In: Gut Environment of Pigs (Eds. A. Piva, K. E. Bach Knudsen, and J. E. Lindberg). Nottingham Univ. Press, City, Country.

Partanen, K. and Z. Mroz . 1999. Organic acids for performance enhancement in pig diets. Nutr. Res. Rev. 12:117-145.

Radecki, S. V., M. R. Juhl, and E. R. Miller. 1988. Fumaric and citric acids as feed additives in starter pig diets: Effect on performance and nutrient balance. J. Anim. Sci. 66:2598-2605.

Ravindran, V. and E. T. Kornegay. 1993. Acidification of weaner pig diets: A review. J. Sci. Food Agric. 62:313-322.

SAS. 1996. SAS User's Guide. Release 6.12 edn. SAS Institute. Inc, Cary, North CA, USA.

Vandenbergh, P. A. 1993. Lactic acid bacteria, their metabolic products and interference with microbial growth. FEMS Microbiol. Rev. 12:221-237.

Walsh, M. C., D. M. Sholly, R. B. Hinson, K. L. Saddoris, A. L. Sutton, J. S. Tadcliffe, R. Odgaard, J. Murphy, and B. T. Richert. 2007. Effects of water and diet acidification with and without antibiotics on weanling pig growth and microbial shedding. J.Anim. Sci. 85:1799-1808.

Wang, J. P., J. S. Yoo, J. H. Lee, H. D. Jang, H. J. Kim, S.O. Shin, S. I. Seong, and I. H. Kim. 2009a. Effect of phenyllactic acid on growth performance, nutrient digestibility, microbial shedding and blood profiles in pigs. J.Anim. Sci. 87:32353243.

Wang, J. P., J. S. Yoo, J. H. Lee, T. X. Zhou, H. D. Jang, H. J. Kim, and I. H. Kim. 2009b. Effects of phenyllactic acid on production performance, egg quality parameters, and blood characteristics in laying hens. J. Appl. Poult. Res. 18:203-209.

Williams, C. H., D. J. David, and O. Iismaa. 1962. The determination of chromic oxide in faeces samples by atomic absorption spectrophotometry. J. Agric. Sci. 59:381-385.

Yin, Y. L., S. K. Baidoo, H. Schulze, and P. H. Simmins. 2001. Effects of supplementing diets containing hulless barley varieties having different levels of non-starch polysaccharides with $\beta$-glucanase and xylanase on the physiological status of the gastrointestinal tract and nutrient digestibility of weaned pigs. Livest. Prod. Sci. 71:97-107.

Zahn, J. A., J. L. Hatfield, Y. S. Do, A. A. Dispirito, D. A. Laird, and R. L. Pfeiffer.1997. Characterisation of volatile organic emissions and wastes from a swine production facility. J. Environ. Qual. 26:1687-1696. 